\title{
Urodimento
}

REVISTA DE ESTUDOS EM ARTES CÊNICAS

E-ISSN 2358.6958

\section{ÉPICO: Processo criativo em pandemia sobre o Teatro Épico de Brecht}

\author{
Mateus Fávero \\ David Atencio
}

Para citar este artigo:

FÁVERO, Mateus; ATENCIO, David. ÉPICO: Processo criativo em pandemia sobre o Teatro Épico de Brecht. Urdimento Revista de Estudos em Artes Cênicas, Florianópolis, v. 2, n. 41, set. 2021.

doi DOI: http:/dx.doi.org/10.5965/1414573102412021e0120

Este artigo passou pelo Plagiarism Detection Software | iThenticate 


\title{
ÉPICO: Processo criativo em pandemia sobre o teatro épico de Brecht ${ }^{1}$
}

\author{
Mateus Fávero² \\ David Atencio ${ }^{3}$
}

\begin{abstract}
Resumo
Este artigo pretende socializar os modos de produção do processo de pesquisa e criação de ÉPICO, da companhia Tercer Abstracto (Chile/Brasil), a fim de responder as perguntas: Como trabalhar as propostas políticas e artísticas de Bertolt Brecht em tempos de pandemia? Como elaborar, a partir do teatro épico, um experimento cênico desenhado para o ambiente virtual? A partir da análise de documentos, das elaborações de pensamento explícito de Tercer Abstracto e do resultado final da peça ÉPICO, pretende-se demonstrar como a pandemia e o tecnovívio afetaram o processo de pesquisa, conduzindo-o para uma experimentação no ambiente virtual acerca das condições de trabalho e organização coletiva em períodos pandêmicos.
\end{abstract}

Palavras-chave: Bertolt Brecht. Teatro Épico. Tercer Abstracto. Metodologias de Pesquisa e Criação. Pandemia.

\section{ÉPICO: Proceso de creación en pandemia sobre el teatro épico de Brecht}

\begin{abstract}
This article aims to socialize the modes of production of the research and creation process of ÉPICO, by Tercer Abstracto company (Chile/Brazil), in order to answer the questions: How to work the political and artistic proposals of Bertolt Brecht in times of pandemic? How to elaborate, from the epic theater, a scenic experiment designed for the virtual environment? From the analysis of documents, the elaborations of explicit thought by Tercer Abstracto and the final result of the piece ÉPICO, it is intended to demonstrate how the pandemic and tecnovivialityaffected the research process, leading it to an experimentation in the virtual environment about the working conditions and collective organization in pandemic times.
\end{abstract}

Keywords: Bertolt Brecht. Epic Theater. Tercer Abstracto. Research and Creation Methodologies. Pandemic.

1 O presente trabalho foi realizado com apoio da Coordenação de Aperfeiçoamento de Pessoal de Nível Superior - Brasil (CAPES) - Código de Financiamento 001 e Beca ANID Chile - Doctorado en el Extranjero.

\footnotetext{
${ }^{2}$ Mestrando em Artes Cênicas na Universidade de São Paulo (USP). fmartins.mateus@gmail.com

(9) http://lattes.cnpq.br/9175323292103737 $\quad$ (iD https://orcid.org/0000-0002-8365-5963
}

${ }^{3}$ Doutorando em Artes Cênicas na Universidade de São Paulo (USP). Mestre em Artes, habilitação em Estudo e Prática do Teatro pela Pontificia Universidad Católica de Chile (2015). deatenci@gmail.com

http://lattes.cnpa.br/2585430918204045 $\quad$ (1) https://orcid.org/0000-0002-1399-0547 


\section{ÉPICO: Pandemic Creation Process on Brecht's Epic Theater}

\section{Resumen}

Este artículo tiene como objetivo socializar los modos de producción del proceso de investigación y creación de ÉPICO, de la compañía Tercer Abstracto (Chile / Brasil), para dar respuesta a las preguntas: ¿Cómo trabajar las propuestas políticas y artísticas de Bertolt Brecht en tiempos de pandemia? ¿Cómo elaborar, desde el teatro épico, un experimento escénico diseñado para el entorno virtual? A partir del análisis de documentos, elaboraciones de pensamiento explícito de Tercer Abstracto y el resultado final de la obra ÉPICO, se pretende demostrar cómo la pandemia y el tecnovivio influyeron en el proceso de investigación, llevándolo hacia una experimentación en entorno virtual sobre condiciones de trabajo y organización colectiva en períodos de pandemia.

Palabras clave: Bertolt Brecht. Teatro Épico. Tercer Abstracto. Metodologías de Investigación y Creación. Pandemia. 
Necessitamos de um teatro que não nos proporcione somente as sensações, as ideias e os impulsos que são permitidos pelo respectivo contexto histórico das relações humanas (o contexto em que as ações se realizam), mas, sim, que empregue e suscite pensamentos e sentimentos que desempenhem um papel de modificação desse contexto.

(Bertolt Brecht, Pequeno Organon para o Teatro, 1948)

Como trabalhar as propostas políticas e artísticas de Bertolt Brecht (1898 1956) em tempos de pandemia? Como elaborar, a partir do teatro épico, um experimento cênico desenhado para o ambiente virtual? Por mais cativantes que estas perguntas sejam, não foram elas que deram início ao processo de pesquisa e criação da peça ÉPICO de Tercer Abstracto ${ }^{4}$. No entanto, inevitavelmente, dadas as circunstâncias impostas pela pandemia e pelo desgoverno brasileiro, estas indagações alteraram os rumos do trabalho do coletivo, consumindo horas de elaboração, paixão e reflexão prática. Este artigo pretende desmembrar o processo de ÉPICO a fim de socializar os modos de produção, demonstrando como essas perguntas afetaram a prática de pesquisa da companhia desde os primeiros ensaios até a estruturação da peça final. Trata-se de uma exposição sobre a prática de pesquisa de Tercer Abstracto, promovida pela própria companhia, que busca produzir "pensamento explícito"5 sobre a produção de conhecimento desenvolvida, a partir da praxis, nesse período adverso (Dubatti, 2020a).

\section{Metodologia de Abstração: a prática como pesquisa em Tercer Abstracto}

Antes de iniciar a exploração sobre ÉPICO, é necessário apresentar alguns antecedentes sobre Tercer Abstracto e sua metodologia de trabalho. Tercer Abstracto é uma companhia de pesquisa e criação em teatro que surge no ano de

Para conhecer o trabalho de pesquisa de Tercer Abstracto, visitar www.tercerabstracto.com.

5 Por "pensamento explícito" entende-se a elaboração meta-artística acerca dos processos de pesquisa e criação desenvolvida pelos próprios artistas. 
2012, em Santiago (Chile), com o objetivo de investigar estratégias de encenação para a elaboração de suas peças a partir das abstrações das artes visuais. Desde 2019, o coletivo se define como binacional, transitando sua criação entre territórios e corpos chilenos e brasileiros. Com as premissas de pesquisar as transformações paradigmáticas das vanguardas artísticas do século XX e friccionar o campo das artes com as ciências, Tercer Abstracto desenvolve duas linhas de pesquisa: a Serie Abstracto e o Projeto Manifestos. A primeira, e mais antiga, pretende criar uma série de nove peças a partir do estudo de nove artistas visuais do período das vanguardas e das neovanguardas ${ }^{6}$

Já o Projeto Manifestos, desenvolvido inteiramente no Brasil, consiste na investigação cênica a partir dos manifestos teatrais que registraram e atestaram muitas das transformações da cena do século XX. A primeira peça do Projeto, CONVENÇ̃̃O, foi criada a partir do manifesto O Teatro da Convenção Consciente (1909) do construtivista Vsevolod Meyerhold. Dando continuidade a esta pesquisa cênica, o processo de ÉPICO parte das elaborações sobre o teatro épico de Bertolt Brecht no seu texto-manifesto Um Pequeno Organon para o Teatro, de 1948.

A prática de pesquisa de Tercer Abstracto é orientada pela "Metodologia de Abstração" (Atencio, 2015), um conjunto de métodos e procedimentos que permitem que a criação se desenvolva como uma prática reflexiva ou como uma reflexão em ação (Borgdorff, 2010), friccionando teoria e prática durante o processo investigativo-criativo. Desse modo, as criações da companhia não pretendem reproduzir as obras cênicas dos artistas teatrais do século XX, no caso do Projeto Manifestos, ou realizar uma transposição do suporte pictórico para o suporte cênico, no caso da Serie Abstracto. A Metodologia de Abstração garante que os princípios dos artistas/manifestos estudados sejam pesquisados de forma performativa durante o processo, momento no qual as artes da cena produzem grande parte de seus conhecimentos. Neste modo de prática como pesquisa, o campo de pesquisa é o próprio processo de criação (Royo e Sánchez, 2010). No

\footnotetext{
${ }^{6}$ Esta nonalogia forma o acróstico ABSTRACTO com as iniciais de cada peça:

ATACAMA (2015) - Mark Rothko (Color Field Painting); BERMUDA (2013) - Lucio Fontana (Espacialismo); S.U.B...C.E.R.O. (2014) - Kazimir Malevich (Suprematismo); TEOREMA (2014) - Wassily Kandinsky (Expressionismo Lírico); ROBOT (em processo) - Jackson Pollock (Action Painting); AZUL (2019) - Yves Klein (Imaterialismo); CROMA (2017) - Josef Albers (Teoria das cores); TEMPO (2018) - Vladimir Tatlin (Construtivismo); O (a definir) - Piet Mondrian (Neoplasticismo).
} 
caso de Tercer Abstracto, a metodologia divide este período de pesquisa e criação em três etapas:

1) Estudos dos Materiais. Uma etapa predominantemente teórica na qual se estuda a produção artística e textual do artista (visual ou cênico) escolhido. Durante este período o coletivo dedica-se ao estudo das etapas de produção do artista, desenvolvendo mapas conceituais e diagramas para a melhor compreensão do objeto de estudo e, ao mesmo tempo, para a compreensão do próprio processo de pesquisa em curso. Esta etapa se concretiza com a elaboração de uma pergunta de pesquisa que dirigirá as próximas etapas e que, invariavelmente, só poderá ser respondida de forma prática, por meio do teatro.

2) Laboratório de Estratégias de Encenação. Esta etapa fricciona constantemente a teoria e a prática. Por meio de exercícios de improvisação e conceitualização, busca-se estratégias práticas e cênicas para responder à pergunta de pesquisa. O fechamento desta etapa ocorre com a definição de uma Estratégia de Encenação, operador prático-conceitual que guiará a montagem da peça.

3) Construção Espaço-Temporal. Esta terceira etapa consiste na construção de materiais cênicos a partir da estratégia levantada no período de laboratório e da estruturação espaço-temporal desses materiais, ou seja, da organização do material no espaço cênico e em um tempo estabelecido.

\section{Primeiras elaborações sobre ÉPICO e a chegada da pandemia}

Para dar continuidade ao Projeto Manifestos em território brasileiro, Tercer Abstracto envia um projeto para um edital de financiamento público em meados de 20197. Neste documento, apresenta-se como meta principal do projeto a “criação e apresentação de uma peça a partir das elaborações organizadas por

\footnotetext{
As primeiras elaborações sobre ÉPICO foram formalizadas no projeto enviado para o ProAC (Programa de Ação Cultural do Estado de São Paulo) com o título Projeto Manifestos: ÉPICO. Entende-se que os projetos de pesquisa e criação são materiais de elaboração de "pensamento explícito" acerca da criação (Dubatti, 2020a). A análise destes materiais vem sendo praticada por estes artistas-pesquisadores, como em "Fávero, Mateus. Orígenes y Transformaciones de AZUL. In: David Atencio (org.). AZUL: Cartografia de Proceso. Santiago: [s.n.], 2020. p. 41-63.
} 
Brecht no texto-manifesto Um pequeno organon para o teatro (1948) sobre o Teatro Épico" (Projeto Manifestos: ÉPICO, 2019, p.4), que se complementa com a seguinte meta específica:

\begin{abstract}
Pesquisar teórica e praticamente acerca dos postulados de Bertolt Brecht sobre o Teatro Épico. O Projeto não tem como fim reproduzir as montagens históricas do encenador ou montar uma peça escrita pelo mesmo. A meta da investigação é a compreensão das elaborações sobre - Teatro Épico com objetivo de gerar metodologias próprias e contemporâneas para a criação cênica (Projeto Manifestos: ÉPICO, 2019, p.4).
\end{abstract}

Deste modo, o que pretendia Tercer Abstracto era desenvolver um projeto de pesquisa e criação a partir das elaborações de Bertolt Brecht em seu textomanifesto, com o objetivo de compreender praticamente o teatro épico, ao mesmo tempo de gerar novas metodologias de criação cênica. Esta premissa se vincula com outra meta específica do projeto: "criar e apresentar ao espectador uma reflexão cênica acerca da história recente do Brasil" (Projeto Manifestos: ÉPICO, 2019, p.4). Naquele momento histórico, a palavra COVID-19 ainda não fazia parte do vocabulário da humanidade. Ninguém poderia supor o que estava prestes a acontecer em todo o mundo. No entanto, algo que se podia constatar, apesar dos pesares, era o desfecho da sequência de derrotas sofridas pela classe trabalhadora brasileira e pelos setores oprimidos da sociedade: a ascensão do neofascismo, personificado na grotesca figura de Jair Bolsonaro. Naquele exato momento histórico, Tercer Abstracto entendia que o estudo de Brecht ajudaria a propor perspectivas de análise para compreender "o que nós somos hoje" - ou o que éramos naquele momento. Afinal, nos épicos momentos que "estamos vivendo, cabe a pergunta: como chegamos até aqui?” (Projeto Manifestos: ÉPICO, 2019, p.6)

O Projeto Manifestos: ÉPICO foi selecionado pelo edital do ProAC em outubro e oficializado em dezembro de 2019. Como em todos os processos de Tercer Abstracto, uma equipe é conformada para levar a cabo a pesquisa e criação do espetáculo ${ }^{8}$. A equipe se reuniu uma primeira vez para a apresentação do projeto

${ }^{8}$ Além de David Atencio (diretor) e Mateus Fávero (ator), Jota Rafaelli (Produtor) e Amanda Tavares Dias 
e outra para buscar horários de ensaio. Logo, todas as certezas foram colocadas em xeque com a chegada da pandemia, que impediu os encontros presenciais. Nas palavras de Dubatti (2020b), o convívio - que é o antecedente e a condição de possibilidade do teatro - foi abruptamente substituído pelo tecnovívio. No convívio, como sempre se trabalhou o teatro, um grupo de pessoas compartilha a mesma territorialidade, na presença física, produzindo experiências a partir da reunião e do encontro. No techovívio emerge uma

experiencia humana a distancia, sin presencia física en la misma territorialidad, que permite la sustracción de la presencia del cuerpo viviente, y la sustituye por la presencia telemática o la presencia virtual a través de la intermediación tecnológica, sin proximidad de los cuerpos, en una escala ampliada a través de instrumentos (Dubatti, 2005, s/p).

Como criar de forma telemática, sem a presença física? Como um coletivo de pessoas que se organiza para trabalhar pela primeira vez, com diferentes práticas metodológicas e sem a memória do convívio nos corpos, poderia desenvolver uma criação? Cabe dizer que, ao princípio, com a ausência de informações em relação a COVID-19, pensava-se que em poucos meses tudo voltaria à "normalidade". Junto com a normalidade, esperava-se ao final do processo apresentar um espetáculo presencial, convivial. Mas, como se verá a seguir, as condições de produção guiaram tanto o processo, como o resultado ao espaço virtual.

(Orientadora Crítico-Pedagógica), que participaram da escrita do projeto, outros trabalhadores da cena ingressam na jornada para a criação de ÉPICO: Vicente Antunes Ramos (dramaturgista), Giovanna Monteiro (atriz), Marô Zamaro (atriz), Paulo Eduardo Rosa (ator), Giu Castro (atriz) e Brendo Trolesi (vídeo e fotografia). Mais adiante outros corpos entram ao processo: Matheus Brant (iluminação), Pablo Serey (música) e João Marcelino (assistência técnica). 
Figura 1 - Registro primeiro encontro do processo. Na foto: David Atencio, equipe criativa na sessão de Zoom e Mateus Fávero. Marzo, 2020. Fotografía: Brendo Trolesi

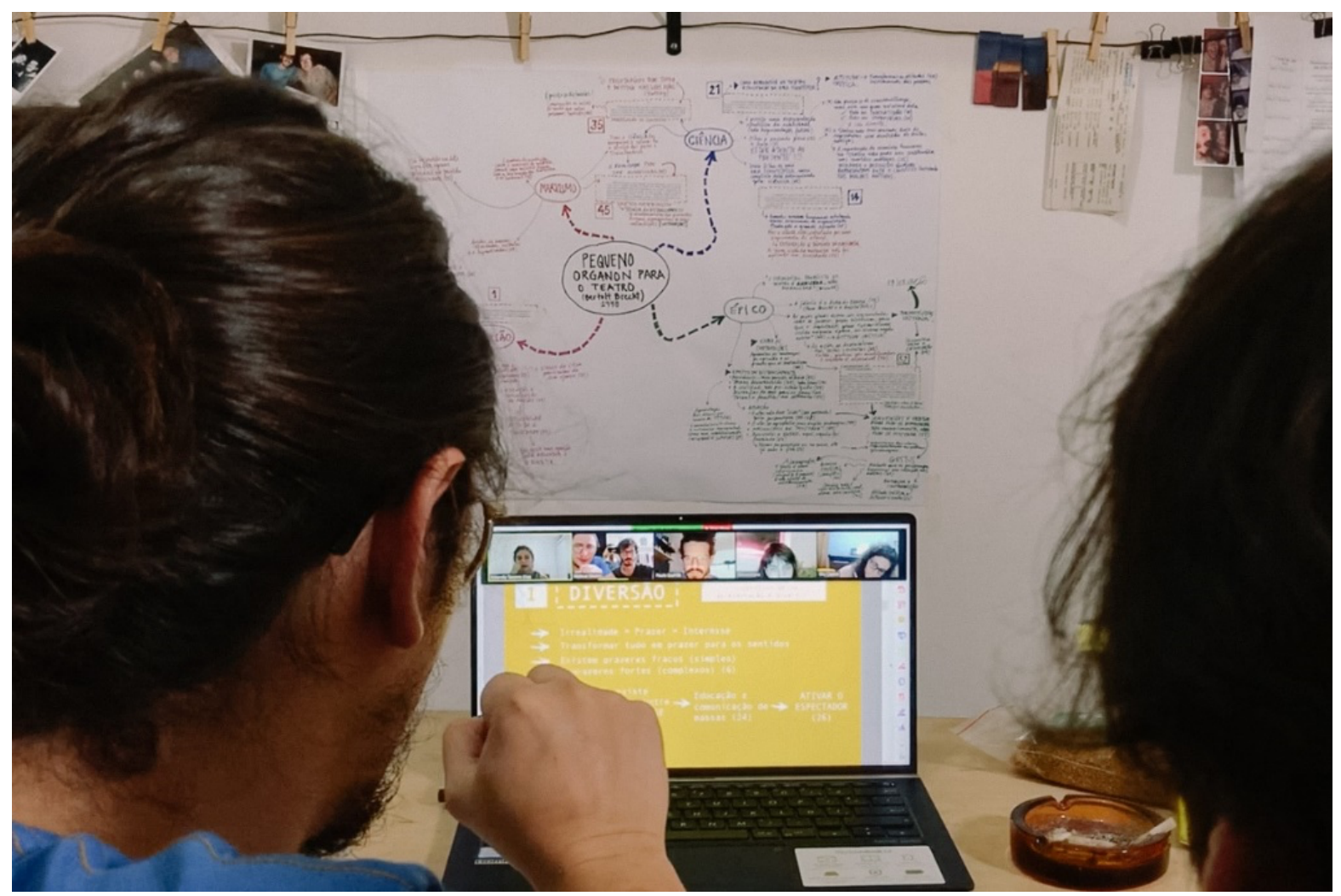

Acervo: Tercer Abstracto

A primeira aposta de Tercer Abstracto, apesar do desafio do tecnovívio, foi a de aferrar-se à metodologia de pesquisa e criação. O caráter investigativo da companhia, de certo modo, prepara os pesquisadores-criadores para o ambiente do desconhecido e do "não saber ainda", criando espaço "para que o impensado, o que é inesperado" possa acontecer ${ }^{9}$ (Borgdorff, 2017, p.111). Este caráter investigativo, com as características metodológicas já explicitadas anteriormente, consiste em uma prática de pesquisa continuada ao longo do tempo. Quando, em 2020, o presidente Donald Trump exigiu da comunidade científica estadunidense a produção de vacinas, a resposta dos cientistas foi que não se pode insultar a ciência e, de repente, insistir que a mesma opere sob demanda, ignorando os

${ }^{9}$ La investigación artística es 'pensamiento material' [...]. Está dirigida más hacia un no saber, o un no saber aún. Crea espacio para lo que es impensado, lo que es inesperado - la idea de que todas las cosas podrían ser diferentes. Esta es la contingencia de la investigación artística. 
recorrentes cortes nos orçamentos ${ }^{10}$. A atual conquista da vacina só foi possível graças aos estudos científicos anteriores, desenvolvidos ao longo do tempo, que serviam como alicerce para a produção daquelas específicas contra o novo coronavírus. A mesma relação se produz na área do teatro. Não existe mágica para a criação em novos formatos, existe experimentação e pesquisa de modo contínuo - e isso não diz respeito apenas aos desafios enfrentados na criação em ambiente virtual. Portanto, em ÉPICO, a metodologia praticada durante anos - apesar das adversidades - foi a base para a estruturação de uma pesquisa e criação no ambiente tecnovivial, tendo em Bertolt Brecht o objeto de pesquisa, mas também a referência principal para a criação.

\section{Primeira Etapa - Estudo dos Materiais}

A primeira etapa contemplou o estudo específico sobre a proposta brechtiana através de um programa de leituras bibliográficas. O programa de estudos articulou-se em seis encontros distribuídos no primeiro mês de trabalho:

ENCONTRO №1 / quinta-feira 19 de março (20h-23h)

O Teatro Épico de Bertolt Brecht

BRECHT, Bertolt. Pequeno Organon para o Teatro em Estudos sobre teatro. Rio de Janeiro: Editora Nova Fronteira (1978), p. 99-134.

ENCONTRO №2 / segunda-feira 23 de março (9h-12h)

Teatro e Marxismo

SÁNCHEZ, José A. La reinvención del teatro: Teatro y Marxismo em Brecht y el expresionismo: reconstrucción de un diálogo revolucionario. La Mancha: Universidad de Castilla (1992), p. 123-129.

ENCONTRO №3 / segunda-feira 30 de março (9h-12h)

As peças didáticas

JAMESON, Fredric. Dualidades do sujeito em O método Brecht. Petrópolis: Editora Vozes (1999). p. 91-101.

BRECHT, Bertolt. Aquele que diz sim e Aquele que diz não. Teatro Completo Vol. 3. São Paulo: Paz e Terra (2004), p. 217-232.

ENCONTRO №4 / quarta-feira 1 de abril (20h-23h)

Interrupção

BENJAMIN, Walter. O que é o teatro épico? Um estudo sobre Brecht (primeira versão). In: Ensaios sobre Brecht. São Paulo: Boitempo (2017), p. $11-21$.

${ }^{10}$ Para mais, ver editorial "Do us a favor", da revista Science de 13 de março de 2020. 
BENJAMIN, Walter. Estudos para a teoria do teatro épico em Ensaios sobre Brecht. São Paulo: Boitempo (2017), p. 31-32.

BENJAMIN, Walter. O autor como produtor em Ensaios sobre Brecht. São Paulo: Boitempo (2017), p. 85-99.

ENCONTRO №5 / terça-feira 7 de abril (20h-23h) - Encontro com Laura Brauer

O olhar épico

BRECHT, Bertolt. As cenas de rua em Estudos sobre teatro. Rio de Janeiro: Editora Nova Fronteira (1978), p. 67-78.

ENCONTRO №6 / quinta-feira 9 de abril (20h-23h)

Pergunta de Investigação

Planejamento e projeção Etapa II

(Atencio, 2020a)

Os encontros realizados de forma remota permitiram reconhecer as etapas de produção do encenador estudado, o contexto de criação do teatro épico e os principais conceitos de sua proposta. A escolha das bibliografias correspondia ao objetivo de conduzir a equipe por um caminho que permitisse compreender as premissas que mobilizaram o encenador. Em termos metodológicos, cabe destacar que esta primeira etapa de estudos da Metodologia de Abstração não é somente um período de leituras, mas uma etapa que convida os participantes a elaborar e estabelecer noções próprias.

De modo geral, esta primeira etapa se finda com a elaboração de uma pergunta de pesquisa, desenvolvida pelos artistas-pesquisadores em processo, baseada nas premissas estudadas anteriormente. Esta pergunta existe para garantir uma investigação prática e a não reprodução da forma do artista estudado, pois entende-se que seu interesse - ou pergunta - foi hipoteticamente respondida com a sua obra e proposta. A pergunta de pesquisa convida os artistaspesquisadores do processo ao campo do desconhecido, a não saber como respondê-la sem praticar. Em outras palavras, é uma pergunta que convida à prática, que mobiliza os pesquisadores e pesquisadoras a sair do estudo teórico para entrar em uma etapa de laboratório e, principalmente, que converte o artista do século passado em uma verdadeira fonte de questionamentos.

No caso particular do projeto ÉPICO, Tercer Abstracto tinha a aposta de explorar historicamente o contexto de produção de Brecht pois considerou-se que 
de alguma forma poderia se espelhar com o atual contexto brasileiro - a ascensão de uma forma política de extrema direita. O pesquisador das vanguardas artísticas, José Antonio Sánchez (1992) descreve o contexto das artes alemãs no período entre guerras como um momento de articulação artística de esquerda. Orientada pelos princípios marxistas, a cena alemã dos anos vinte desenvolveu diversas expressões que tentaram articular uma arte proletária. Analisando o teatro proletário expressionista e as inovações cênicas do encenador Erwin Piscator (1893 - 1966) como antecedentes da prática brechtiana, Sánchez descreve a pugna entre a esquerda para o desenvolvimento de um teatro marxista. Se por um lado, o expressionismo pós-primeira Guerra Mundial parecia amador e panfletário demais para os intelectuais, por outro, as refinadas técnicas de montagem cênica de Piscator resultaram abstratas e incompreensíveis para uma massa proletária (Sánchez, 1992). Entre as duas tentativas, havia os aderentes de uma arte como meio para a divulgação de ideias e agitação de massas, e havia outros que preferiam uma arte de complexo funcionamento que pudesse expressar, de melhor forma, os interesses culturais e sociais da esquerda do contexto. Nesse embate, o pesquisador coloca a figura de Brecht como uma terceira via, uma terceira tentativa que consegue, por um viés metodológico, superar a fronteira entre forma e conteúdo presente nos antecedentes apresentados. O pesquisador espanhol identifica três dificuldades da estética marxista do contexto alemã que foram reorganizadas na proposta de Bertolt Brecht: 1) A problemática da forma, 2) A problemática da recepção de massas e 3) A problemática da conexão com os espectadores.

A resposta brechtiana às dificuldades identificadas por Sánchez corresponde a uma análise específica do trabalho de Brecht em seus primeiros anos de produção. Mais do que confrontar as problemáticas de maneira formal, Brecht, aos olhos de Sánchez, desenvolveu um mecanismo metodológico que foi expresso na produção de suas peças didáticas ou lerhstück. Entre 1928 e 1930, Brecht produziu cinco processos experimentais ${ }^{11}$ que liquidaram a questão estética para atingir o

${ }^{11}$ Com o objetivo de ressaltar o caráter de experimentação das peças didáticas de Brecht, expõe-se o trabalho desse período como processos experimentais, mais do que espetáculos. Os cinco trabalhos dessa etapa de produção são: O vôo sobre o Oceano (1928); A peça didática de Baden-Baden sobre o acordo (1929); Aquele que diz sim / Aquele que diz não (1929); A decisão (1930); e A exceção e a regra (1930). Esta última é considerada uma obra híbrida entre a produção de peças didáticas e o teatro épico (Gonçalves, 2016). 
objetivo pedagógico de ensinar dialética aos espectadores e participantes do processo criativo. Realizadas em sindicatos e escolas, as peças didáticas tinham o objetivo de desenvolver novas formas de atuação política. Para isso, eram realizadas como trabalhos experimentais em pleno desenvolvimento e não como espetáculos previamente articulados por um coletivo ou encenador. Colocando os espectadores como produtores do espetáculo, as peças didáticas eram realizadas como trabalhos de improvisação modelada. A partir de estruturas dramatúrgicas móveis, as lerstücke convocavam os espectadores a deixarem de ser contempladores para serem atores da encenação, refletindo em cena os argumentos e comportamentos das personagens previamente modeladas.

Apresentando a ideia de um teatro como um laboratório científico, Brecht dispunha a encenação como um lugar de "exame das relações sociais e acontecimentos históricos" (Gonçalves, 2016, p.279), propondo uma observação crítica por partes dos espectadores-participantes. Apagando o princípio imitativo da realidade presente no teatro - e nas artes como um todo - dos séculos anteriores, as peças didáticas eram "dispositivos experimentais de aprendizagem e investigação coletiva”12 (García, 2016, p.4), superando, por um lado, a crítica dos intelectuais de esquerda sobre a arte panfletária dos expressionistas, e por outro, apresentando um mecanismo orgânico para os participantes que superava a complexidade formal do teatro de Piscator. Este teatro, de forte caraterística científica, captou a atenção do processo, determinando espontaneamente o interesse de Tercer Abstracto na produção das peças didáticas e oferecendo uma perspectiva de pesquisa particular para o próprio processo de criação: como desenvolver hoje, no atual contexto do Brasil, um teatro didático? Como apresentar um dispositivo de participação dos espectadores que ofereça ferramentas políticas? Como realizar essa ação pedagógica em formato on-line?

A partir dessas perguntas, o estudo foi direcionado para os interesses sobre os mecanismos empregados pelo próprio Brecht para atingir seus objetivos políticos-estéticos. Para o terceiro e quarto encontro, o grupo refletiu, a partir das leituras de Fredric Jameson (1999) e Walter Benjamin (2017), sobre os

12 No original: "experimental devices for collective learning and research". (Tradução nossa) 
procedimentos brechtianos. Mais do que um interesse nos recursos formais do artista estudado - no caso de Brecht, por exemplo, poderia ser o uso de músicas ou de projeções documentais -, Tercer Abstracto tem o interesse em analisar os procedimentos conceituais por trás das formas desenvolvidas pelo artista em seu contexto. Esta estratégia metodológica corresponde ao objetivo de pesquisar, teórica e praticamente, procedimentos próprios que permitam a reatualização das premissas do artista estudado, com os olhos e recursos da contemporaneidade, e não a simples reprodução dos mecanismos empregados pelo artista - neste caso, Brecht - há um século.

No capítulo Dualidades do sujeito, Jameson (1999) oferece uma análise conceitual do operador empregado por Brecht na peça Aquele que diz sim / Aquele que diz não.

Aqui se exige tanto da plateia quanto dos atores uma simplificação radical da experiência. Uma redução da ação e do gesto ao mínimo da decisão enquanto tal, numa situação em si mesma reduzida ao mais mínimo maquinismo da escolha (Jameson, 1999, p.94).

Analisando a diferença entre representação direta e abstração cênica, Jameson explica que o trabalho de Brecht pode ser considerado minimalista e experimentalista, pois emprega simplificações e reduções da experiência que expressam, de forma explícita, as decisões das personagens de suas fábulas. Diferenciando entre aparências e conhecimentos, o crítico estabelece que o olhar científico de Brecht não recai sobre o operador de mimese, mas na observação gestual e comportamental das ações das personagens, propondo uma observação analítica que transforme a realidade e que não simplesmente a reproduza. Assim, o operador identificado por Jameson apresenta um dualismo que coloca as ações das personagens da ficção em diálogo com as interpretações e análises de quem as executa - o ator ou a atriz -, expondo de forma concreta tanto as decisões que estão sendo escolhidas, como aquelas que estão sendo omitidas.

Assim como a resposta apresentada por Sánchez sobre a terceira via metodológica de Brecht, que oferece uma solução à problemática panfletária identificada do teatro expressionista, Jameson, décadas depois, critica a prática brechtiana de seus contemporâneos, dizendo que a reprodução das mensagens políticas de Brecht esvazia o verdadeiro poder revolucionário de sua prática. Na 
visão de Jameson, o caráter transformador do jovem Brecht - referindo-se ao período de produção das peças didáticas - recai exatamente na aplicação de um dispositivo teatral que desorganiza a encenação, colocando os espectadores no centro da ação cênica, discutindo e analisando os comportamentos das personagens - como cientistas em um laboratório - e não apenas reproduzindo mensagens panfletárias sobre ideais políticos. Essa visão é compartilhada por Benjamin (2017) que analisa que o palco deixa de ser espelho da realidade, para se transformar em tribuna, dizendo que é "um teatro no qual o conhecimento não é apenas transmitido, mas gerado" (Benjamin, 2017, p.19). Essa tribuna é a situação das peças de Brecht.

Benjamin ofereceu para o processo de ÉPICO um segundo procedimento para compreender a operação do teatro brechtiano: a interrupção. Assim como em um tribunal os juízes interrompem as declarações das testemunhas para extrair delas dados específicos que ajudem a compreender as circunstâncias das ações dos culpados, o teatro de Brecht tem o objetivo, na leitura de Benjamin (2017), de interromper a ação para tornar consciente as decisões por trás de tais atitudes, tanto para os atores que executam as ações, como para os espectadores que estão analisando os comportamentos. Ao invés de manter a ilusão de uma realidade, o teatro brechtiano rompe e interrompe a sequência das ações para analisá-las. Para Benjamin (2017), o teatro de Brecht é principalmente um teatro gestual, pois expõe os comportamentos das personagens não a partir das falas que podem ser enganosas -, mas das ações, atitudes e gestos que expõem as decisões e as intenções por trás dos comportamentos. Em síntese, Benjamin declara que "o teatro épico não reproduz situações; antes, as revela. A revelação das situações acontece por meio da interrupção dos processos" (Benjamin, 2017, p.14), a qual traz para a atuação brechtiana um novo recurso que destrói a representação realista.

No teatro épico, a formação do ator consiste numa atuação que o leva ao conhecimento; esse conhecimento, por sua vez, determina sua atuação não apenas no sentido do conteúdo, mas também por meio de tempos, pausas e ênfases. Não se trata de questão de estilo (Benjamin, 2017, p.19). 
Concluindo a primeira etapa do processo de ÉPICO, alguns eixos conceituais foram levantados para conduzir as atividades posteriores. Entretanto, não foi possível, em virtude das dificuldades geradas pelo isolamento social e o trabalho virtual, formalizar uma pergunta de pesquisa. A virtualidade limitou alguns recursos que beneficiam o processo de construção da pergunta de forma coletiva, como a discussão "desorganizada" e o trabalho com lousa, no qual os artistaspesquisadores constroem conjuntamente um quadro conceitual. Pela primeira vez no trabalho de Tercer Abstracto, o período de laboratório não foi orientado por uma pergunta de pesquisa, mas por premissas, eixos conceituais: 1) a dimensão política e dialética, que oferece opções - tanto para os atores, como para os espectadores - de análise dos comportamentos das personagens; 2) a dimensão de participação ativa dos espectadores na construção do espetáculo; 3) a escolha de uma situação social para ser analisada e 4) o objetivo de transformação da realidade social e política.

\section{Período de rearticulação}

Junto com a esperança de que a pandemia de COVID-19 acabasse e, com ela, as dificuldades práticas de realizar um processo de pesquisa criativa de forma remota, o grupo decidiu realizar um período de interrupção - assim como a reflexão que Benjamin extrai do teatro de Brecht. Esse período tinha como objetivo analisar as possibilidades criativas e investigativas nesse novo contexto. Após dois meses de reuniões, o grupo decidiu realizar uma rearticulação do projeto cênico original. Adaptando-se à realidade tecnovivial, o coletivo reorganizou a segunda etapa de criação - o laboratório de estratégias de encenação - para o formato virtual. Decidiu-se por manter a pesquisa em relação ao teatro de Brecht, mas abandonar as primeiras projeções cênicas do espetáculo13. Dado o contexto, agrega-se um quinto eixo conceitual ao processo: como elaborar, a partir das premissas anteriores, um experimento cênico desenhado para o ambiente virtual?

Para dar início à segunda etapa de pesquisa, decidiu-se investir no caráter

${ }^{13}$ No projeto original enviado para o ProAC, tinha-se a ideia cênica de trabalhar com aparelhos de reprodução e registro de som, baseando-se na atividade jornalística. 
científico do teatro brechtiano. Para consolidar tal decisão, a direção propôs trabalhar sobre o conceito de modelo científico, projetando como estratégia de encenação a ação de modelar.

\section{Segunda Etapa - Laboratório de estratégias de encenação}

Neste ponto, cabe explicar que o projeto inicial contava com duas perspectivas acerca da palavra épico, que dá título à peça trabalhada. Por um lado, a relação específica com o estudo da proposta brechtiana, e por outro, o uso coloquial da palavra, que se refere a um momento importante, único ou histórico. Em termos criativos e de pesquisa, Tercer Abstracto convidou os criadores e criadoras, desde o princípio, a discutir os “épicos momentos que estamos vivendo". Com a estratégia de encenação de modelar, o coletivo iniciou a análise do momento conjuntural - uma pandemia avassaladora em mãos de um governo fascista - para o desenvolvimento do laboratório.

A seguir, apresenta-se o documento enviado por e-mail pelo diretor ao grupo criativo expondo a programação dos vinte dias de laboratório, em formato on-line, distribuídos em dois meses.

\section{ETAPA II - LABORATÓRIO DE ESTRATÉGIAS DE ENCENAÇÃO}

A etapa de laboratório (Etapa 2) é de caráter teórico-prático. Está destinada a explorar mecanismos, procedimentos e estratégias de encenação que vinculam o estudo teórico anterior com um projeto de criação artística. Em particular, para esse projeto se propõe a estratégiahipótese de modelar como base do trabalho de laboratório.

\section{Progresso da Pesquisa Artística}

O projeto tem um avanço acumulativo dividido em dois meses de trabalho.

1. Modelo (sessões 1 - 4): corresponde ao estudo e proposição criativa da equipe a partir do conceito de modelo, começando pelas noções científicas de representação e aprendizado da natureza e sistemas (Física e Filosofia, de Mario Bunge), para depois aprofundar novamente nas peças didáticas a partir do modelo de ação (Baden Baden, de Vicente Concilio).

O objetivo desses 4 encontros será discutir e projetar possibilidades criativas para abordar o modelamento como estratégia de 
encenação. Para isso, realizaremos encontros com propostas individuais para uma aproximação com a ação de modelar.

2. Materiais a serem modelados (sessões 5 - 10): a partir das nossas primeiras aproximações com a ação de modelar, tentaremos praticar como modelar alguns materiais. A escolha desses materiais é influenciada pelo próprio trabalho de Brecht, quem na tentativa de reproduzir no teatro a sociedade, utilizava assuntos específicos para serem debatidos (se fossemos físicos, provavelmente modelaríamos fenômenos naturais como o movimento ou a força; se fossemos construtivistas russos, modelaríamos o trabalho do corpo humano ou a flexibilidade de materiais rígidos como a madeira ou o metal; como somos brechtianistas proponho que esse seja o universo material a ser modelado).

O objetivo desses 6 encontros será modelar esses materiais, aplicar a análise e ser criativos para refletir sobre o Épico momento que estamos vivendo.

3. O espectador dentro dos nossos modelos (sessões 11 - 16): tendo aproximações concretas de modelos com o Épico momento, vamos nos debruçar na complexa pergunta por como introduzir o espectador dentro desses modelos, ou nos perguntar por como interagir com o espectador a partir desses modelos. Exploraremos em tentativas de comunicação à distância: internet, videochamada, etc. qualquer coisa que permita responder à necessidade de inserir o espectador dentro desse sistema-modelo criado por nós (o objetivo não deverá ser nunca um exercício formal de interação com espectadores à distância, mas sim uma materialização do modelo com o espectador).

O objetivo é ter mecanismos que apresentem a ação de modelar esses materiais específicos para/com os espectadores. A ideia é começar a elucidar a partir da prática o vínculo pedagógico discutido na nossa primeira etapa, aproximando-nos do que chamamos de teatro-assembleia ou teatro como uma grande aula.

4. Apresentação (sessões 17 - 20): para finalizar nossa etapa de laboratório teremos que testar nossas aproximações com espectadores reais. Propõe-se, então, uma abertura de processo que será criada especialmente para corroborar ou testar nossas ideias e aproximações sobre Brecht.

(Atencio, 2020b).

O documento expõe quatro atividades para a realização da segunda etapa de laboratório. Em síntese, propõe: debruçar-se sobre os modelos científicos (4 sessões); uma exploração sobre materiais temáticos (6 sessões); uma exploração cênica em formato on-line sobre a participação dos espectadores dentro do exercício (6 sessões); e finalmente, a realização de uma abertura de processo que 
apresente os resultados práticos e criativos do laboratório (4 sessões).

A noção de modelo científico orientou as ações durante o processo de laboratório. A partir de leituras teóricas sobre modelamento - estudaram-se os textos Física e Filosofia de Mario Bunge (2015) e Modelo de Ludwig Boltzmann (2013) -, o coletivo se aproximou das problemáticas analíticas da ciência e da potencialidade criativa de representação de fenômenos a partir da abstração científica.

Para a ciência, os modelos são ferramentas epistêmicas que ajudam a compreender fenômenos complexos de forma simplificada. Os modelos são esquematizações e abstrações de fenômenos reais, mecanismos que fornecem "uma imagem, por analogia, de um fenômeno da natureza" (Roque; Videira, 2013, p.288). Os modelos não são concebidos para descrever a realidade, "mas constituem somente uma ilustração mecânica, concebida com o propósito de ajudar o entendimento" (Roque; Videira, 2013, p. 288) tal qual o teatro de Brecht.

Metodologicamente, Tercer Abstracto trabalharia a ação de modelar por meio de improvisações estruturadas e coletivas, mas pelas dificuldades que a virtualidade impôs para o processo, optou-se por realizar exercícios individuais para o levantamento da estratégia de encenação. 
especialistas em Brecht ${ }^{14}$. Suas intervenções dentro do processo guiaram uma reflexão sobre a forma de como organizar a estrutura do espetáculo. O grupo, a essa altura do processo, indagava pelo material específico a ser trabalhado, ou melhor, modelado - na linguagem empregada dentro do processo -, para a compreensão dos épicos momentos que estavam vivendo. Foi assim que a peste bubônica emergiu como um material capaz de gerar reflexões e analogias com a atual pandemia do coronavírus, suscitando perguntas como: O que podemos aprender do passado para transformar o hoje?

A segunda etapa culminou em uma abertura de processo, realizada a finais de agosto de 2020, que selecionou e organizou os exercícios produzidos no laboratório em três unidades independentes: a primeira explorava a participação dos espectadores por meio do dispositivo de cartelas $^{15}$; a segunda narrava os acontecimentos da peste bubônica, estabelecendo paralelos com a pandemia atual, com a linguagem de teatro de sombras; e a terceira unidade propunha duas situações específicas da Idade Média para que o público pudesse analisá-las e tomar partido.

Esta estrutura, após a sua apresentação e avaliação grupal, foi mantida como alicerce do processo de construção da terceira e última etapa do projeto.

\section{Terceira Etapa - Construção Espaço-Temporal}

O objetivo metodológico da terceira etapa de construção espaço-temporal consiste em criar uma estrutura cênico-dramatúrgica que conduza os espectadores através dos conteúdos e premissas exploradas nas etapas anteriores. A construção da montagem teve início com a premissa de criar um espetáculo que analisasse - e entregasse as ferramentas de análise aos

${ }^{14}$ Vicente Concilio, autor do livro Baden-Baden: Modelo de ação e encenação no processo com a peça didática de Bertolt Brecht (2016), conversou com o coletivo sobre a sua pesquisa doutoral sobre o teatro didático, oferecendo uma perspectiva pedagógica sobre os objetivos brechtianos. Laura Brauer, pesquisadora argentina radicada em São Paulo, compartilhou estratégias de análise e de atuação brechtianas, trabalhando com o grupo análises a partir de dois filmes de Brecht: Os carrascos também morrem (1943) e Kuhle Wampe (1932).

${ }^{15}$ Slides de PowerPoint que eram compartilhados pela plataforma zoom com o público. Os espectadores e espectadoras eram convidados a ler o que estava escrito nessas cartelas, como personagens em uma peça de teatro. 
espectadores - as diferenças e semelhanças entre os acontecimentos pandêmicos do atual coronavírus e da peste bubônica da Idade Média. Organicamente, o emprego do modelamento como operador conceitual estratégia de encenação - foi sendo reduzido à ação de comparar. A comparação funcionou, desse modo, como um instrumento - modelo - oferecido ao público a fim de despertar sua perspectiva crítica e analítica.

Faltando três meses para a estreia do espetáculo, o coletivo decidiu recorrer mais uma vez à teoria. No entanto, dessa vez o objeto de estudo não foi Brecht, mas a peste bubônica. O objetivo desse novo estudo era produzir uma tabela comparativa entre a Idade Média e o Brasil atual que, por sua vez, serviria de base para a estruturação do espetáculo. O livro de Silvia Federici, Calibã e a Bruxa (2017), foi a principal bibliografia deste período. A autora apresenta uma perspectiva materialista-histórica e feminista sobre as transformações das relações das mulheres com a sociedade no percurso da História. Para isso, o livro parte com uma análise sobre as mudanças sociais decorrentes da peste bubônica, destacando uma história de fortes lutas camponesas e proletárias a favor dos direitos trabalhistas. As palavras da historiadora italiana repercutiram de forma sensível e intelectual no processo criativo de ÉPICO. O grupo descobriu, a partir dos estudos, uma perspectiva histórica que não apresentava a Idade Média como uma sociedade estagnada politicamente, mas como um momento de grandes lutas e rebeliões que tentaram alterar as relações de poder entre as classes sociais da época. Federici apresenta como a peste acelerou os processos sociais em curso e como os trabalhadores e trabalhadoras da Idade Média se organizaram para reivindicar os direitos de sua classe.

O que se seguiu tem sido descrito como a 'idade de ouro do proletariado europeu' (Marx, 1909, t.1; Braudel 1967, pp. 128 e segs.), algo muito distinto da representação canônica do século XV, que foi imortalizado iconograficamente como um mundo sob a maldição da dança da morte e do memento mori. Thorold Rogers retratou uma imagem utópica deste período em seu famoso estudo sobre os salários e as condições de vida na Inglaterra medieval. 'Em nenhum outro momento', escreveu Rogers, 'os salários foram tão altos e a comida tão barata' (Federici, 2017, p.100).

Com este acúmulo teórico, decidiu-se por reorientar as unidades 
experimentadas na abertura de processo para a seguinte estrutura:

- Unidade 1: a partir de uma situação performativa (o jogo de cartelas lidas pelos espectadores que reproduzia operação das peças didáticas de Brecht), oferecer uma ferramenta de leitura para as próximas unidades.

- Unidade 2: narrar, em formato de teatro de sombras, a história medieval da peste bubônica, ressaltando os elementos de transformação política, cultural e social impulsionados pela pandemia.

- Unidade 3: apresentar personagens vivenciando a pandemia no Brasil atual em situações análogas às apresentadas anteriormente, expondo as decisões e circunstâncias de forma explícita para a análise dos espectadores.

Frente ao desafio da construção do espetáculo e contemplando a necessidade de criar novas cenas para materializar três unidades com linguagens completamente diferentes, optou-se pela divisão do coletivo em três núcleos com funções específicas. Esta decisão foi relevante e corresponde a uma consequência das condições de produção. Nesse contexto de pandemia, obrigados a trabalhar à distância e restringidos a sete meses de trabalhos pelo financiamento do edital público obtido, foi uma decisão arriscada que permitiu acelerar o processo de construção dos materiais, ao mesmo tempo de garantir a possibilidade de criação coletiva, em núcleos, e não individual, como os exercícios que vinham sendo praticados até então.

O trabalho processual funcionou, em cada núcleo, de forma diferente. Cada unidade da peça exigia da equipe criativa materiais e modelos de trabalho distintos. Para o desenvolvimento da primeira unidade, a escrita dramatúrgica foi de extrema relevância. Para a segunda, o trabalho artesanal com figuras recortadas exigia um tempo de trabalho completamente distinto. E para a terceira unidade, o trabalho de improvisações por meio da plataforma digital, articulando uma ficção de duas personagens no interior de um apartamento. Bem como no teatro de Brecht, no qual "o ator tem diversas funções, e seu estilo de atuar se modifica de acordo com as funções exercidas" (Brecht apud Benjamin, 2017, p. 19), 
os criadores e criadoras de ÉPICO tiveram que desenvolver diferentes funções por vezes distantes de suas práticas mais consolidadas. Por exemplo, ninguém na equipe trabalhava com teatro de sombras antes do processo, mas a necessidade da criação de tal material mobilizou parte do grupo a desenvolver esta prática.

Figura 3 - Ensaio de manipulação de teatro de sombras para o espetáculo ÉPICO. Na foto: Mateus Fávero e Marô Zamaro. Dezembro, 2020. Fotografia: David Atencio.

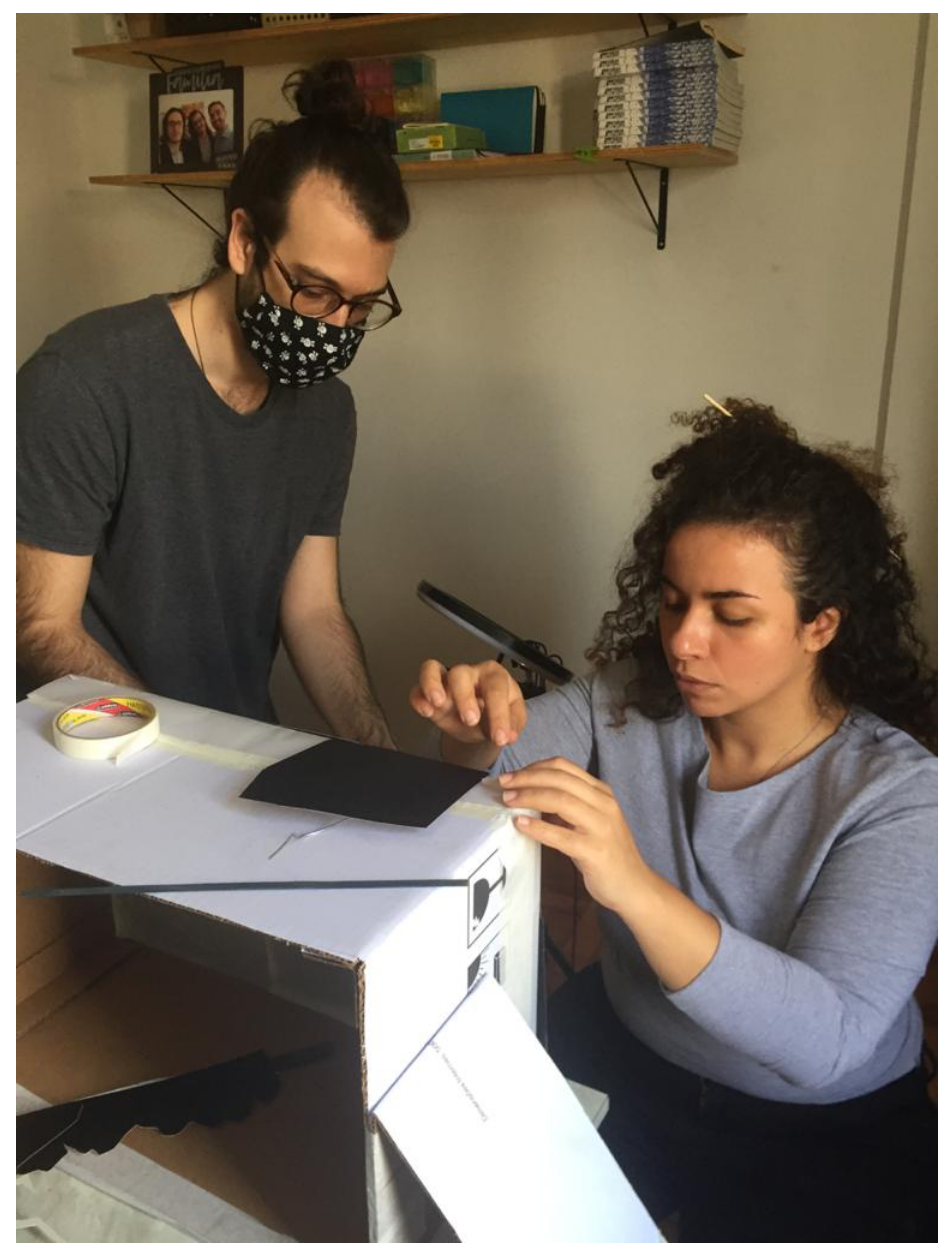

Acervo: Tercer Abstracto

Apesar do benefício técnico e produtivo, a divisão em núcleos provocou uma certa centralização da criação na direção. Para organizar as três unidades em um espetáculo coeso, a direção participava dos ensaios de todos os núcleos. Estes, por sua vez, trabalharam de forma independente e apresentavam seus avanços de processo em ensaios coletivos.

A adversidade do trabalho a distância, compartilhada nas etapas anteriores, 
foi amplificada no trabalho em grupo, como a dificuldade de ensaiar o teatro de sombras por meio do zoom ou a ausência do convívio para as improvisações. No entanto, a rigorosidade metodológica, junto com o desenvolvimento coletivo das etapas anteriores, possibilitou a criação do espetáculo final.

Desejou-se, até o último momento, apresentar o espetáculo on-line ao vivo, em tempo real. Entretanto, inclusive esta aspiração teve de ser modificada por conta do contexto. Para a última unidade, projetava-se que a atuação - no interior do apartamento - acontecesse no ambiente do convívio e que fosse transmitida na plataforma virtual. No entanto, no último mês de trabalho, após alguns ensaios com máscaras e álcool gel, parte da equipe - os autores deste artigo - contraíram a COVID-19 - que se manifestou de forma assintomática. Este evento gerou temor em todo o coletivo e impossibilitou que a maior parte do espetáculo - com exceção da unidade 1 - fosse realizada ao vivo. Optou-se, então, por adiar a estreia. Três semanas após o ocorrido, a equipe se organizou para gravar de forma presencial a segunda e a terceira unidade, em dias separados, e contando apenas com os integrantes necessários para levar a cabo cada cena. Escolheu-se, também, realizar as gravações pela mesma plataforma Zoom com a qual haviam ensaiado, ao invés do trabalho com câmeras profissionais. Esta decisão afirmou uma fidelidade ao processo de criação e aos modos de produção.

\section{Concluindo com os espectadores}

Muito se discutiu, ao longo deste longo período pandêmico, sobre as criações cênicas virtuais. Uma pergunta recorrente, tanto no âmbito da criação como no âmbito acadêmico, era de caráter ontológico e resumia-se a: “isso é teatro?". A diretora chilena Manuela Infante, propondo uma alternativa à discussão essencialista, responde: "El teatro por streamingES, de eso no hay duda. La pregunta que importa es ¿Qué hace?” (Infante, 2020, n/p.). Qual relação propõe para com o público? Quais noções políticas e estéticas emergem da criação? Qual é o "pensamento implícito" por trás dos construtos e das estruturas? Luiz Fernando Ramos escreve que: 


\begin{abstract}
O teatro possível enfrenta o impossível. [...]. Épico da Cia. Tercer Abstracto parte de uma investigação honesta sobre um projeto canônico do século 20, o teatro épico, mas alcança, além de estabelecer uma versão inventiva, de raro frescor, sobre o seu ponto de partida, uma resposta franca às urgências do tempo. Tanto frente ao pandemônio em que o Brasil, ou seu desgoverno, transformou a pandemia, como às demandas dos meios disponíveis às encenações, sem abrir mão de alguma simultaneidade presencial e de vero impacto sobre os espectadores (Ramos, 2021, p.1)
\end{abstract}

Destrinchando as elaborações críticas de Ramos, pode-se destacar que a prática de pesquisa em relação ao teatro épico, neste contexto específico, gerou respostas tanto no que tange a produção de presença e a utilização dos meios virtuais para a criação cênica, como para a situação política e pandêmica do Brasil de 2020. Para Brecht, estas esferas não se dividem. O teatro e suas potencialidades emergem como recurso para a análise - com fins de transformação - da realidade.

José Fernando Azevedo (2020) relembra que a "teoria do rádio" e da "refuncionalização do aparelho" de Brecht podem ser úteis para pensar o processo de criação no ambiente virtual. Isto não significa uma transposição mecânica das elaborações do encenador sobre o rádio para o zoom ou a internet, mas abrem velhos-novos olhares para o que está sendo produzido atualmente. Brecht (2007) analisava que o rádio estava funcionando como um aparato de distribuição, como mero repartidor, e não como um instrumento de comunicação. Para tanto, propõe a "refuncionalização" do aparelho, ou seja, a transformação de aparato distribuidor em aparato de comunicação. Portanto

o rádio seria o mais admirável aparato de comunicação que se poderia conceber na vida pública, um enorme sistema de canais; quer dizer, seria, caso ele se propusesse não somente a emitir, mas também a receber; ou, não apenas deixar o ouvinte escutar, mas fazê-lo falar; e não o isolar, mas colocá-lo numa relação. O rádio deveria, portanto, sair da esfera do fornecimento e organizar o ouvinte como fornecedor. Por isso, são absolutamente positivos todos os esforços do rádio quanto a imprimir nos assuntos públicos um caráter realmente público (Brecht, 2007, n/p).

Este processo de transformação dos modos de produção do aparelho rádio implicaria em uma ativação dos espectadores e espectadoras, que passariam da recepção passiva para a produção, do mesmo modo que os modelos de ação das 
peças didáticas e o próprio teatro épico fizeram com o teatro. Esta perspectiva de Brecht consistia em uma

compreensão do fazer teatral pelos espectadores como um processo de democratização e socialização dos meios de produção, possibilitando que o ato do espectador possa se realizar como um ato artístico, autoral, produtivo (Desgranges, 2017, p.52).

ÉPICO, de três diferentes formas ao longo de sua estrutura, buscou essa refuncionalização do meio virtual e socialização dos modos de produção. Na primeira unidade da peça, apresentada como uma espécie de prólogo ou introdução, busca-se proporcionar com o público - e não entregar para ele - uma chave-conceitual sobre a qual a peça irá trabalhar, a noção sobre a "necessidade e dificuldade de falarmos juntos". Ao longo do espetáculo, esta dificuldade poderá ser associada com a organização de luta da classe trabalhadora e dos movimentos sociais, tanto na Idade Média como no Brasil atual. No entanto, neste primeiro momento, a "dificuldade de falar juntos" aparece de forma performativa, no sentido de que é o próprio público quem desenvolve a ação e ativa a peça por meio da leitura das cartelas pré-desenhadas e compartilhadas na tela do zoom. Este primeiro momento proporciona uma quebra da expectativa do "ir a ver" um espetáculo para "produzir o espetáculo", pois sem a participação - ainda que não convivial - do público, a peça não avança. As cartelas convocam os espectadores e espectadoras a falar e, em determinado momento, a fazê-lo juntos. No entanto, o delay próprio da conectividade e a característica da ferramenta de comunicação incidiam sobre participação do público, promovendo a dificuldade de se falar em coro.

A segunda unidade da peça trabalha com outro recurso para a democratização dos meios de produção. Diversas sombras se materializam, nas mesmas telas do Zoom, para dar forma à narração - um recurso épico no sentido literário - sobre o impacto da peste bubônica na organização das lutas e nas relações de poder da Idade Média. Durante quase quinze minutos o público acompanha o desfile das sombras, até que outras câmeras entram em ação para revelar a manipulação das formas animadas. Este distanciamento manifesta as 
condições da criação por trás da história, mostrando o caráter artesanal das figuras e das sombras. Este é o primeiro momento da peça em que corpos reais aparecem em cena, e estes corpos aparecem trabalhando, mostrando que por trás daquela ficção existe uma construção. Como observa Luiz Fernando Ramos:

se revela plenamente o dispositivo construtor daquele encantamento: os manipuladores no exercício de constituir as imagens aparecem em ação, contrastados em simultaneidade com as próprias, desvendando o processo criativo e acrescentando-lhe em paralelo sua dissecação ao espectador. Esta nova camada imagética já acena para o épico na perspectiva específica do teatro de Brecht (Ramos, 2021, p.1).

Por último, a terceira unidade coloca o público frente a uma situação aparentemente dramática de duas personagens de classe média, dentro de um apartamento, que se veem afetados pela pandemia (desemprego, demissão, dificuldade em pagar as contas) e, ao mesmo tempo, não se reconhecem como classe trabalhadora e não veem uma saída na organização coletiva. No entanto, os atores cristalizam em cena o processo de criação vivido, questionando suas próprias personagens. Praticando o modelo de ação durante o processo de improvisação, os atores analisavam as atitudes e decisões das personagens e propunham novas circunstâncias e novas decisões para elas. Giulia Castro, atriz do processo, explica que a limitação de se trabalhar dentro de um apartamento

impõe uma situação dramática, de indivíduos, e que a classe protagonista da discussão que a gente (sic) queria trazer - que são os entregadores, os metroviários, os professores - não cabe em um apartamento. Eles estão fora do apartamento. Então a gente (sic) foi buscando entender como esses dois indivíduos [...] iam sendo atravessados por essa coisa que não está dentro do apartamento. (Bate-papo ÉPICO, 2021).

Esta atitude analítica do processo se mantém na peça final, fazendo com que os atores se apresentem como atores, para além das personagens, e compartilhem suas análises e propostas com o público, a fim de despertar um pensamento crítico sobre os eventos: o que eu faria se estivesse nessa situação? E, ao final, o desenlace para a disjuntiva entre o possível de se representar (o interior do apartamento) e o não representável (a classe trabalhadora) ganha forma com a retomada do teatro de sombras, um recurso da ordem do épico, 
capaz de representar um coro, uma multidão organizada na rua pela transformação social.

Do ponto de vista formal, a peça de conjunto não obedece a uma estrutura dramática, mas episódica -- e, portanto, épica. Três unidades que, em conjunto, propõem uma experiência sensível e analítica, política e estética. O trabalho de modelar, ou de comparação, não é realizado pelas personagens camponesas da Idade Média ou pelas personagens da "cena de apartamento", mas pelo espectador e espectadora de ÉPICO.

A pandemia afetou de modo transversal o processo de Tercer Abstracto, desde as condições de produção, passando pela metodologia, até a temática da obra. Foi este contexto que propiciou e deu condições - ainda que adversas - para esta experiência comparativa. O que podemos aprender com o passado? Quais são as semelhanças e diferenças entre os épicos momentos de 1348 e de 2020/21? A peça apresenta materiais e fatos, mas também perspectivas e posicionamentos. No entanto, durante o espetáculo, é o público quem - ativamente e de forma produtiva - trabalha o sentido crítico. Como escrito na sua sinopse, ÉP/CO é "uma peça on-line, um jogo de comparações que pretende proporcionar ferramentas de análise". Além do mais, "tratando as condições sociais como acontecimentos em processo", a peça "pretende suscitar, como escreveu Brecht, pensamentos e sentimentos que desempenhem um papel na modificação do contexto". ${ }^{16}$

\section{Referências}

ATENCIO, David. Memoria de Creación de "Atacama": Metodología de Abstracción a partir del Color Field Painting de Mark Rothko. 2015. Dissertação (Mestrado em Artes) - Facultad de Artes de la Pontificia Universidad Católica de Chile, Santiago, 2015.

ATENCIO, David. ÉPICO: Etapa / (Estudo dos Materiais). Mensagem recebida por ggiovannamonteiro@gmail.com ramos.vicente.antunes@gmail.com amanda.dias@usp.br, giuliaconfuorto@gmail.com, edu.rosa62@gmail.com,_jotarafaelli@gmail.com, fmartins.mateus@gmail.com, zamaromaro@gmail.com. Data de recebimento: 13 mar. 2020 a. 
ATENCIO, David. ÉPICO: Proposta Etapa /l. Mensagem recebida por <giuliaconfuorto@gmail.com,_jotarafaelli@gmail.com,_amanda.dias@usp.br, edu.rosa62@gmail.com, fmartins.mateus@gmail.com, ggiovannamonteiro@gmail.com, ramos.vicente.antunes@gmail.com, zamaromaro@gmail.com, brendotrolesi@gmail.com. Data de recebimento: 12 jun. 2020 b.

AZEVEDO, José Fernando P. "Entre o gatilho e a tempestade": racismo, capitalismo, teatro e a capacidade mimética de um vírus (notas de trabalho para desdobramentos futuros, na encruzilhada-Brasil). 2020. Disponível em <https://www.n-1edicoes.org/textos/3>. Acesso em: 7 jun. 2021.

BATE-PAPO ÉPICO. São Paulo: Arquivo Digital Tercer Abstracto. Abril, 2021. Vídeo, 48 min., son., cor. Disponível em: <https://youtu.be/P9z3MsWoeYY>. Acesso em 9 de julho de 2021.

BENJAMIN, Walter. Ensaios sobre Brecht. São Paulo: Boi Tempo, 2017.

BOLTZMANN, Ludwig. Modelo. Revista Scientiae Studia, São Paulo, v.11, n.2, p. 381389, 2013.

BRECHT, Bertolt. O rádio como aparato de comunicação: Discurso sobre a função do rádio. Estudos Avançados, São Paulo, v. 21, n.60, n.p. 2007. Disponível em <https://www.scielo.br/j/ea/a/tkGMW6LYSKjLJJQFWxy4JRH/?lang=pt>. Acesso em 7 de junho de 2021.

BUNGE, Mario. Física e filosofia. São Paulo: Perspectiva, 2015.

BORGDORFF, Henk. ¿Dónde estamos hoy? El estado del arte en la investigación artística. Entre Diálogos, v.3, n. 3, p. 102-113, novembro, 2017.

BORGDORFF, Henk. El debate sobre la investigación en las artes. Cairon: Revista de Ciencias de la Danza, Alcalá de Henares: Servicio de Publicaciones de la Universidad de Alcalá, n. 13, p. 25-46, 2010.

CONCILIO, Vicente. BadenBaden: Modelo de ação e encenação no processo com a peça didática de Bertolt Brecht. Jundiaí: Paco Editorial, 2016.

DESGRANGES, Flávio. La mediación cultural: Estrategias para fomentar la relación entre el espectador y la escena teatral. Paso de Gato: Revista Mexicana de Teatro, Ciudad de México, n. 70, p. 50-52. 2017.

DUBATTI, Jorge. Artistas-investigadoras/es y producción de conocimiento territorial desde el teatro: hacia una Filosofía de la Praxis. In: DUBATTI, Jorge (org.). Artistas-investigadoras/es y producción de conocimiento territorial desde el teatro: Una Filosofía de la Praxis Teatral. Lima: ENSAD, 2020a, p.19-45.

DUBATTI, Jorge. Experiencia teatral, experiencia tecnovivial: ni identidad, ni campeonato, ni superación evolucionista, ni destrucción, ni vínculos simétricos. Rebento, São Paulo, v. 1, n. 12., p.9- 32. 2020b. 
DUBATTI, Jorge. Fragmentos - Cultura teatral y convívio. In: Revista Conjunto, no 136. 2005. Disponível em:

http://casadelasamericas.org/publicaciones/revistaconjunto/136/dubatti.htm.

Acesso em: 02 jun. 2021.

FEDERICI, Silvia. Calibã e a bruxa: mulheres, corpos e acumulação primitiva. São Paulo: Elefante, 2017.

GARCÍA, Luis Ignacio. Bertolt Brecht, ignorant master. 2016. Disponível em: https://www.academia.edu/4200095/Bertolt_Brecht_ignorant_master.

Acesso em: 23 maio 2021.

GONÇALVES, Natalia. A 'didática' nas peças didáticas de Bertolt Brecht: ensino em cena. (Doutorado em Educação Escolar) - Faculdade de Ciências e Letras, Universidade Estadual Paulista, Araraquara, 2016.

INFANTE, Manuela. Teatro por streaming y el derecho a la opacidad. Revista Hiedra, 2020. Disponível em: https://revistahiedra.cl/opinion/teatro-por-streaming-y-elderecho-a-la-opacidad/.Acesso em: 7 jun. 2021.

JAMESON, Fredric. O método Brecht. Petrópolis: Editora Vozes, 1999.

ROQUE, Tatiana; VIDEIRA, Antonio. A noção de modelo na virada do século XIX para o século XX. Revista Scientiae Studia, São Paulo, v.11, n.2, p.281-304, 2013.

ROYO, Victoria Pérez; SÁNCHEZ, José Antonio. La investigación en artes escénicas. Introducción. CAIRON: Revista de Estudios de Danza, Madrid, n. 13, p. 5-13, 2010.

SÁNCHEZ, José Antonio. Brecht y el expresionismo. La Mancha: Universidad de la Castilla, 1992.

Projeto Manifestos: ÉPICO. Arquivo Digital Tercer Abstracto. Julho, 2019.

Disponível em: <https://drive.google.com/file/d/1ql8wqAl-

C6efR5rveRJvemXFagqF_Em9/view?usp=sharing>. Acesso em: maio 2021.

Recebido em: 15/06/2021

Aprovado em: 19/08/2021 